\title{
Fires in Tunnels: Experiments and Modelling
}

\author{
E. Cafaro ${ }^{1, *}$ and V. Bertola ${ }^{2}$ \\ ${ }^{I}$ Politecnico di Torino, Dipartimento di Energetica, Corso Duca degli Abruzzi 24, 10129 Torino, Italy \\ ${ }^{2}$ I.S.I. Foundation, Viale Settimio Severo 65, 10133 Torino, Italy
}

\begin{abstract}
The development of fire safety research in road tunnels during the past 20 years is reviewed, with particular reference to the activity of the Flame Research Group at Politecnico di Torino (Italy). Simulations of fire accidents in tunnels are described for both full-scale tests in real tunnels and for laboratory-scale tests. It is shown how simple semiempirical thermo-fluid dynamic models are able to capture the fire dynamics and the behaviour of the smoke layer observed in experiments. The results provide a basis to develop rational design criteria and safety regulations.
\end{abstract}

Keywords: Tunnel fires, full-scale fire test, tunnel fire modelling, risk analysis.

\section{INTRODUCTION}

During the past decade, a number of tunnel fires with several casualties occurred in Europe: Mount Blanc (FranceItaly, 1999, 39 casualties); Tauern (Austria, 1999, 12 casualties); Gotthard (Switzerland, 2001, 11 casualties); Frejus (Italy, 2005, 2 casualties). Following these catastrophic events, the EU undertook actions to reduce the scially acceptable risk in tunnels of its rail and road networks. Hence prevention and protection strategies attracted serious attention, and two fundamental documents defining minimum safety requirements were published $[1,2]$. The same documents recommend the use of risk analysis methods to assess tunnels safety.

The safety of European tunnels was assessed and found generally poor. Investigation reports describe under-sized systems, designed on the basis of a limited number of simplified scenarios instead of realistic fire scenarios [3-7]. In particular, current safety regulations refer to small vehicle fires (cars or small trucks) without spreading to other vehicles, which were probably found in the literature, with typical heat release rates (HRRs) in the range 20-30 MW [8-12].

All of the above mentioned Alpine tunnels were equipped with transversal ventilation systems, which were expected to remove the smoke generated by a fire and allow people to escape according to the current design best practice. Whilst all of these tunnels had previously experienced several heavy goods vehicle (HGV) fires, none of which developed into a catastrophic fire, their ventilation systems were not able to remove smoke from the fire scene.

The critical analysis of such a negative scenario was however necessary in order to build up a rational set of design criteria and safety guidelines and regulations based on a more realistic description of the physical phenomena involved in tunnel fires. In particular, the appropriate

*Address correspondence to this author at the Politecnico di Torino, Dipartimento di Energetica, Corso Duca degli Abruzzi 24, 10129 Torino, Italy; Tel: +39 011 5644476; Fax: +39 011564 4499;

E-mail: emilio.cafaro@polito.it quantification of tunnel fire risk requires the fire scenario to be described in probabilistic terms instead of using some arbitrary data available in technical handbooks.

In this context, the Flames Research Group at Politecnico di Torino produced a significant effort aiming at a deeper understanding of tunnel fires through field experiments as well as mathematical modelling [13-27].

The results of these studies, together with the awareness that any variables related to fire accidents have a stochastic nature, led to the development of guidelines for risk assessment [25] and of a probabilistic method for the risk analysis of road and railway tunnels (IRAM - Italian Risk Analysis Method) [22-26].

\section{EXPERIMENTS ON FIRES IN TUNNELS}

The open literature describes several full-scale fire tests in tunnels [28-33], the most important of which are summarized in Table 1 (the list is by no means exhaustive, however). A fire test is conceived as a controlled fire event where characteristic parameters (such as the mass burning rate, the temperature field and pressure gradients) are measured and recorded for further analysis.

Fire tests can be designed to measure the effectiveness and the reliability of fire detection systems, the real performances of installed ventilation systems, or to characterize the indoor air quality and the smoke layer evolution.

Moreover, they allow one to test new equipments, materials, detection systems, as well as to train firefighters and first aiders to rescue injured people and those in danger, to evaluate the fire size by mapping the thermal field, to control the smoke generation and flow, and to reduce the thermal damage on structures.

The design stages of a fire test can be summarised as:

- functional classification of the tunnel (according e.g. to its destination, or its structural features);

- definition of the reference fire source (the fuel choice and its mass determine the duration of the controlled event): 
Table 1. Most Significant Full-Scale Tunnel Fire Tests

\begin{tabular}{|c|c|c|c|l|c|c|c|}
\hline Name & Type & Year & Country & \multicolumn{1}{|c|}{ Fire source } & Area & HRR & Ventilation \\
\hline \hline Ofenneg & Rail & 1965 & Switzerland & petrol pool & $24 \mathrm{~m}^{2}$ & $15-25 \mathrm{MW}$ & $\begin{array}{l}\text { natural, longitudinal, } \\
\text { semi-transversal }\end{array}$ \\
\hline Zwenberg & Rail & 1976 & Austria & petrol pool & $24 \mathrm{~m}^{2}$ & $15-25 \mathrm{MW}$ & $\begin{array}{l}\text { natural, longitudinal, } \\
\text { semi-transversal }\end{array}$ \\
\hline Rapperfijord & $\begin{array}{c}\text { Mining } \\
\text { gallery }\end{array}$ & $1990-92$ & Norway & $\begin{array}{l}\text { train wagons, cars, HGV, } \\
\text { calibrated fires }\end{array}$ & $30-40 \mathrm{~m}^{2}$ & $15-100 \mathrm{MW}$ & longitudinal, transversal \\
\hline Memorial & Road & $1993-95$ & USA & diesel oil pool & $60 \mathrm{~m}^{2}$ & $10-100 \mathrm{MW}$ & longitudinal, transversal \\
\hline Colli Berici & Road & 1999 & Italy & $\begin{array}{l}\text { petrol/diesel oil pools, car } \\
\text { mockup }\end{array}$ & $60 \mathrm{~m}^{2}$ & $2-5 \mathrm{MW}$ & natural \\
\hline Rosa & Road & 2002 & Italy & calibrated fires, cars, van & $60 \mathrm{~m}^{2}$ & $2-20 \mathrm{MW}$ & natural, longitudinal \\
\hline Runehamar & Road & 2003 & Norway & $\begin{array}{l}\text { pellets, plastic, tyres, HGV } \\
\text { mockup }\end{array}$ & $32.5 \mathrm{~m}^{2}$ & $70-200 \mathrm{MW}$ & longitudinal \\
\hline
\end{tabular}

- liquid fuel pools (pool fire);

○ solid combustible stacks (crib fire);

$\circ$ vehicles and burning goods;

- preliminary numerical simulations, obtained from the solution of proper field and zone models to obtain estimates of the smoke propagation velocity, and of temperature and velocity fields inside the tunnel, for fires of different magnitude and for different ventilation regimes, using either commercial or open source codes;

- functional lay-out and definition of instrumentation, which typically includes:

- load cell with digital data acquisition system to measure the burning rate;

- grids of anemometers to characterize the velocity field;

$\circ$ portable anemometers to measure the gas velocity in the smoke extraction openings (dampers, stacks);

0 grids of thermocouples and aspiration pyrometers to characterize the temperature field;

- Pitot pipes for the measurement of the pressure variations induced by the fire;

- linear temperature detector to localize the fire source;

- $\mathrm{O}_{2}, \mathrm{CO}$, and $\mathrm{CO}_{2}$ concentration sensors;

- smoke opacimeters;

- definition of the visualization system, composed of:

o fixed thermo-cameras to map the temperature field;

- vehicle mounted video-cameras to estimate the convective heat transfer coefficient and for the determination of the space-time variation of the smoke layer height;

○ auxiliary video-camera;
- design of the tunnel protection system in the following steps:

o estimation of the maximum wall and devices temperatures;

0 definition of the protecting materials and size of shields;

- organization of safety service for support staff, which requires:

o protecting the environment outside the tunnel from smoke;

- protecting support staff during preliminary setting up and during tests;

$\circ$ extinguishing the fire in case of emergency.

\subsection{Full-Scale Experiments}

Full-scale tests are expensive and the characteristic size of the structures limits the possibility to install a complete set of instruments as well as the total number of experiments which can be undertaken. Whilst large-scale tests provide an impressive picture of tunnel fires, they always failed to provide sufficient data to fully validate functional relationships obtained in laboratory tests.

A full-scale fire test was carried out in the "Colli Berici" tunnel near Vicenza (Italy) in December 1999 [14]. The characteristics of fires, which were positioned in the middle of the tunnel, are summarized in Table 2.

Table 2. Characteristics of the Fire Tests in the "Colli Berici" Tunnel

\begin{tabular}{|c|c|c|}
\hline & $\mathbf{1}^{\text {st }}$ test & $\mathbf{2}^{\text {nd }}$ test \\
\hline \hline Burning materials & $\begin{array}{c}\text { Gasoline: } 601 \\
\text { Diesel oil: } 301 \\
\text { Water: } 451\end{array}$ & $\begin{array}{c}\text { Gasoline: } 1401 \\
\text { Car tyres: } 12 \\
\text { Truck tyres: } 1 \\
\text { Wood pallets: } 12 \\
\text { Mattresses: } 4\end{array}$ \\
\hline Fire size & $1.2 \mathrm{~m}$ & $3 \mathrm{~m}$ \\
\hline Heat Release Rate & $2-2.5 \mathrm{MW}$ & $4.5 \mathrm{MW}$ \\
\hline Max. temperature & $420^{\circ} \mathrm{C}$ & $750^{\circ} \mathrm{C}$ \\
\hline Duration & $20 \mathrm{~min}$. & $30 \mathrm{~min}$. \\
\hline
\end{tabular}


Five temperature measurement stations equipped with grids of $\mathrm{K}$ thermocouples (suspended from the vault using Fisher ring hooks) were placed along the tunnel length. Thermocouples directly exposed to fire were protected with a ceramic coating, while those placed far enough from flames had a $0.5 \mathrm{~mm}$ fibreglass covering. Hot junctions were fixed to the grid nodes, so that the temperature distribution on the relevant cross-sections of the tunnel could be recorded by a data acquisition system in the control room through cables running along the tunnel walls (protected with $40 \mathrm{~mm}$ rock wool in zones expected to reach the highest temperatures). All connectors were protected with a ceramic shell and aluminium film.

Fig. (1). shows the layout of the test tunnel with the relevant instrumentation and the control room, separated from the test zone by a brick wall and containing a data logger with voltage stabilizer and connected to a PC. The data acquisition system was operated at 6 samples per minute.

The smoke visualization system, shown in Fig. (2), consisted of a tubular chassis supporting two orthogonal can- vases illuminated by an array of lights; the system was mounted on a towed truck, and recorded the evolution and propagation of the smoke layer. By synchronizing the thermocouple signals with the camera images, the system could measure both the smoke propagation velocity and the convective heat transfer coefficient.

Fig. (3). shows the measured burning rate of fuel during the first test, and compares it with the predictions of Vibe's model [34]. Finally, Fig. (4). displays the temperature evolution at different positions in the tunnel.

In 2002, a second full-scale test was carried out in the Rosa tunnel, an abandoned road tunnel near Trento (Italy) [19]. Before the test, the tunnel was equipped with a longitudinal ventilation system, a fire detection system (opacimeter, linear temperature detector, video smoke detector), emergency lighting system, acoustic escape guide, CCTV system, fire mitigation system, and tunnel management and control system.

The instrumentation, which was connected to a digital acquisition and measurement system to record and analyze

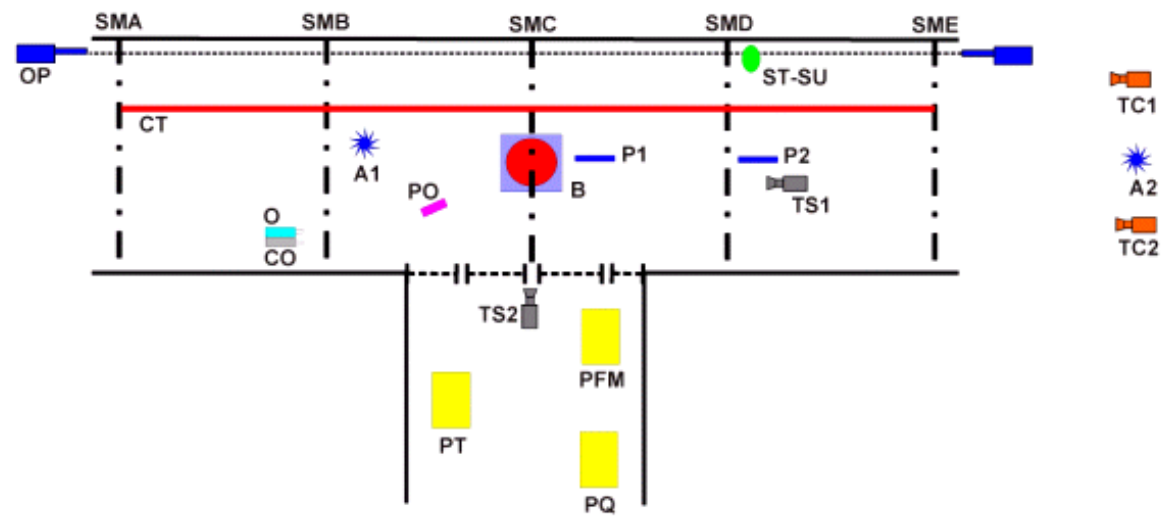

Fig. (1). Layout of the test tunnel equipped with: digital scale (B); optical pyrometer (P); temperature (ST) and relative humidity (SU) sensors; Pitot pipes (P1,P2); anemometers (A1, A2); carbon monoxide (CO) and oxygen (O) sensors; opacimeter (OP); thermo-sensitive cable (CT); IR cameras (TC1, TC2); cameras (TS1, TS2); thermocouple grids (SM).

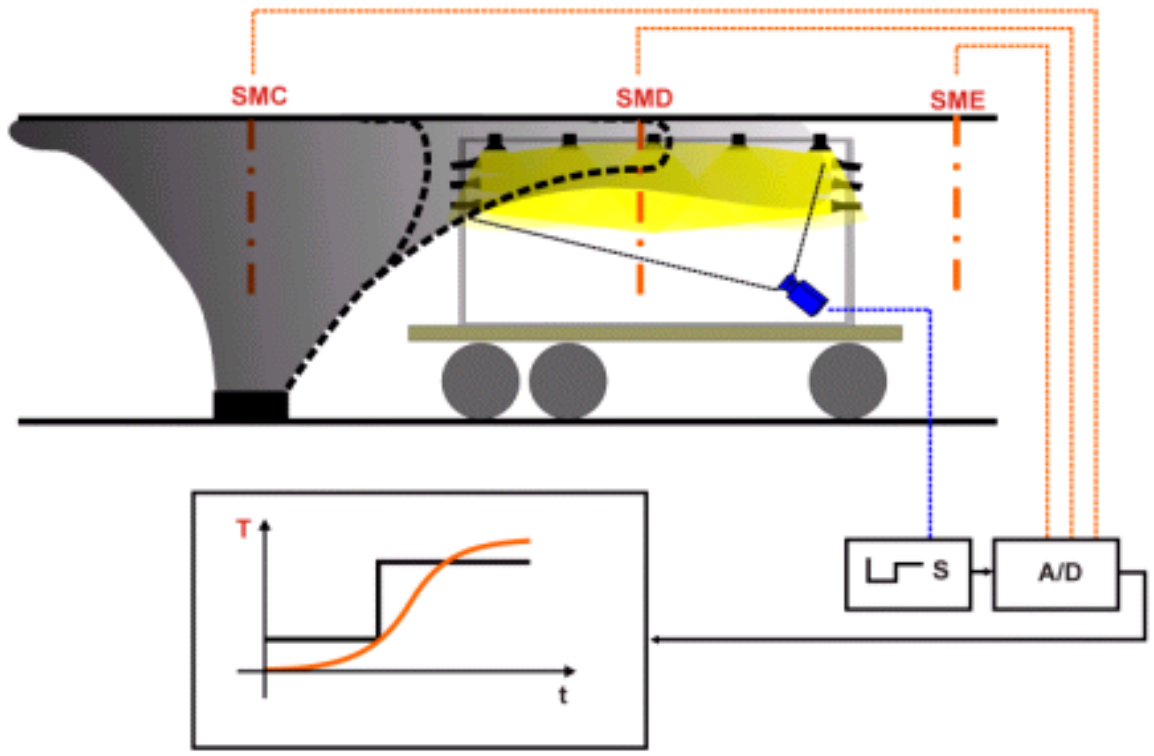

Fig. (2). Smoke visualization system. 


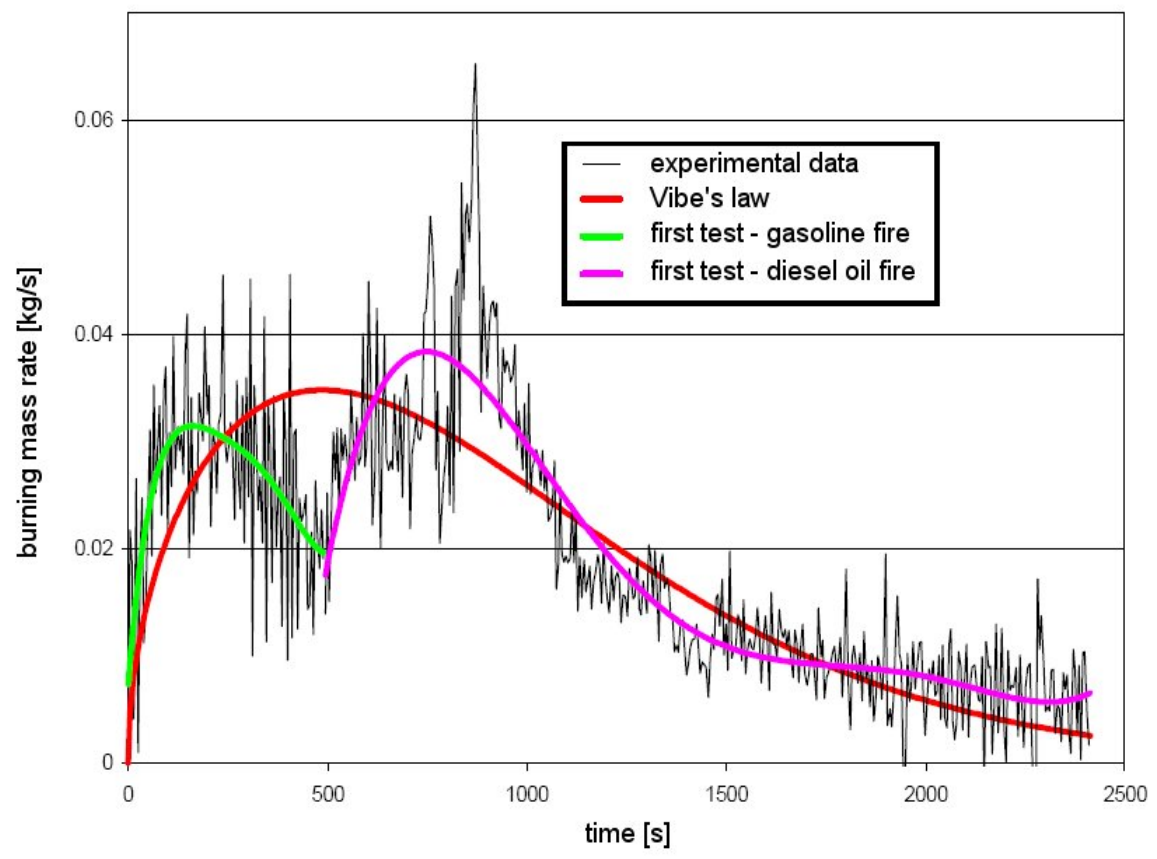

Fig. (3). Burning rate of fuel during the first test in Colli Berici tunnel [14] and comparison with Vibe's law.
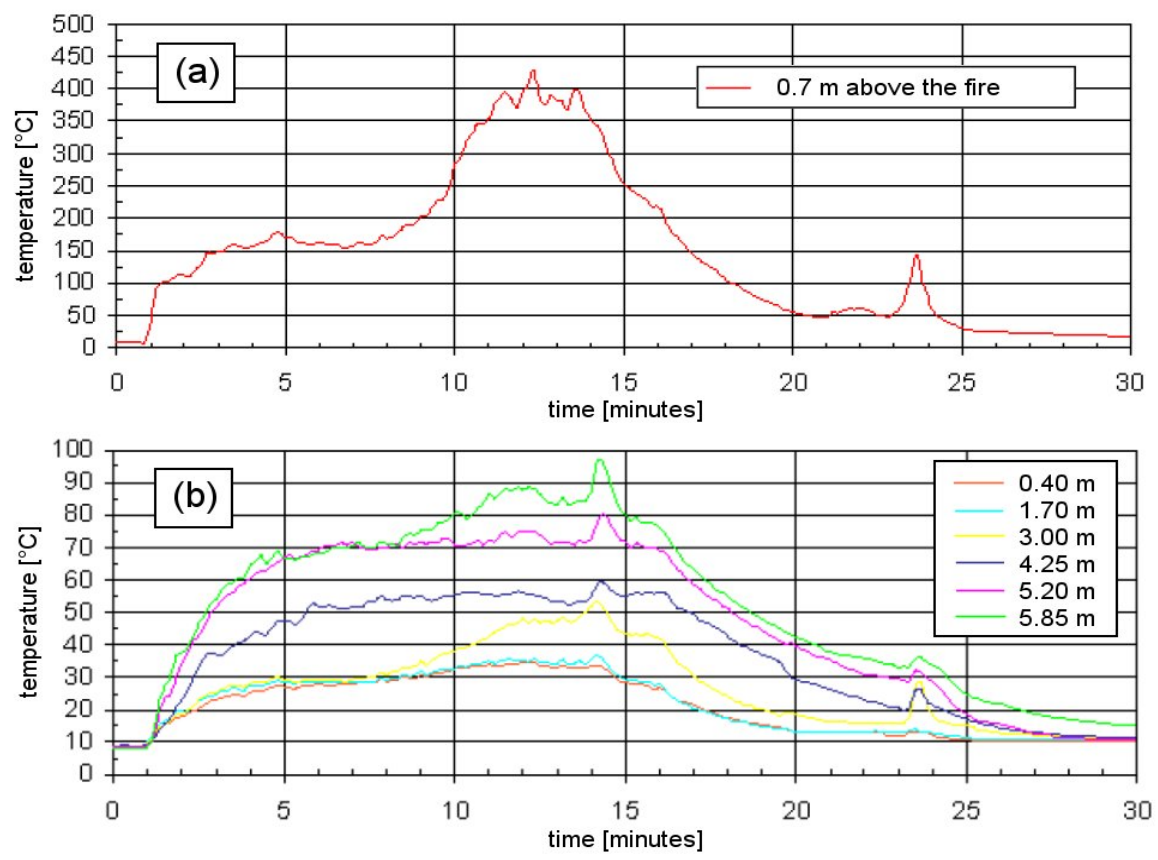

Fig. (4). Temperatures measured at station SMC above the fire (a) and SME $50 \mathrm{~m}$ downstream (b).

the burnt mass, temperature, air velocities and species concentrations, included the following components:

- 1 PC Notebook;

- 1 NI Field Point network and 32 MB CPU module;

- 4 NI Field Point 8 channel 16 bit thermocouple modules;

- 2 NI Field Point 8 channel 16 bit analogue input modules;

- 32 type $\mathrm{K}$ thermocouples mounted on 5 poles;
- 32 anemometers;

- 1 Pitot tube;

- $2 \mathrm{CO}$ and $2 \mathrm{CO}_{2}$ sensors;

- 1 opacimeter;

- 4 DS Europe 500 kg load cells;

- 1 Mettler BAS $300 \mathrm{~kg}$ digital scale;

The temperature measurement system was organised at different points uniformly distributed at suitable distances from both sides of the fire source. The measurement posi- 
tions were chosen to follow a log-Tchebychev distribution of grid points, so that the average temperature was equal to the arithmetic mean of the measured values. The same scheme was adopted for velocity measurements.

Fig. (5). shows the smoke stratification during a pool fire test using diesel oil as fuel (maximum heat release rate: 2 MW), 53 seconds after ignition. The measured heat release rate and temperatures in correspondence of the fire source are reported in Fig. (6).

In a second test, the effectiveness of a water mist mitigation system was tested on a light commercial vehicle fire. Fig. (6) shows a picture of a burning van at the moment of activation of the mitigation system, while the time evolution of the most significant tenability parameters (man height

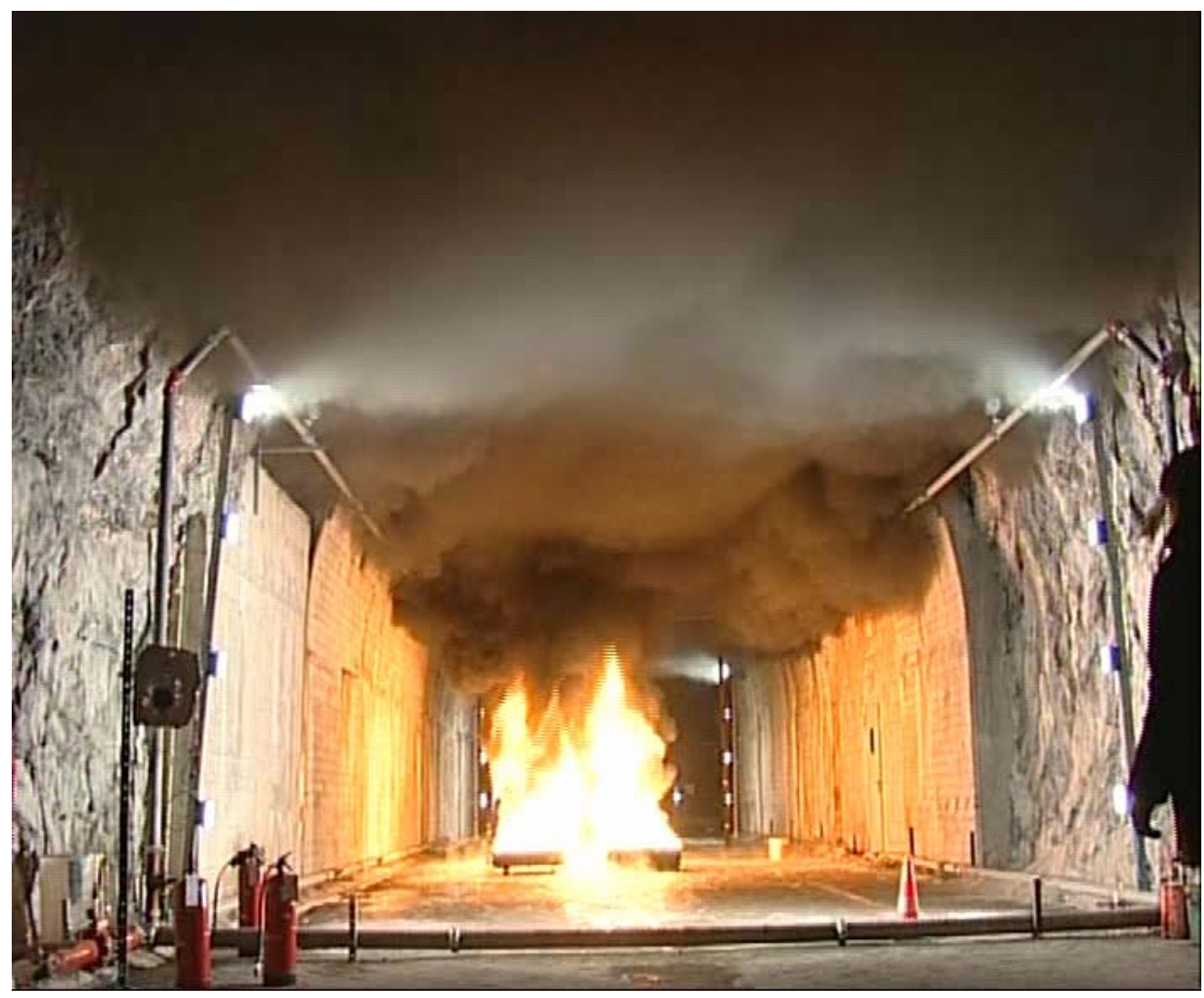

Fig. (5). Smoke stratification during a pool fire test in the Rosa tunnel.

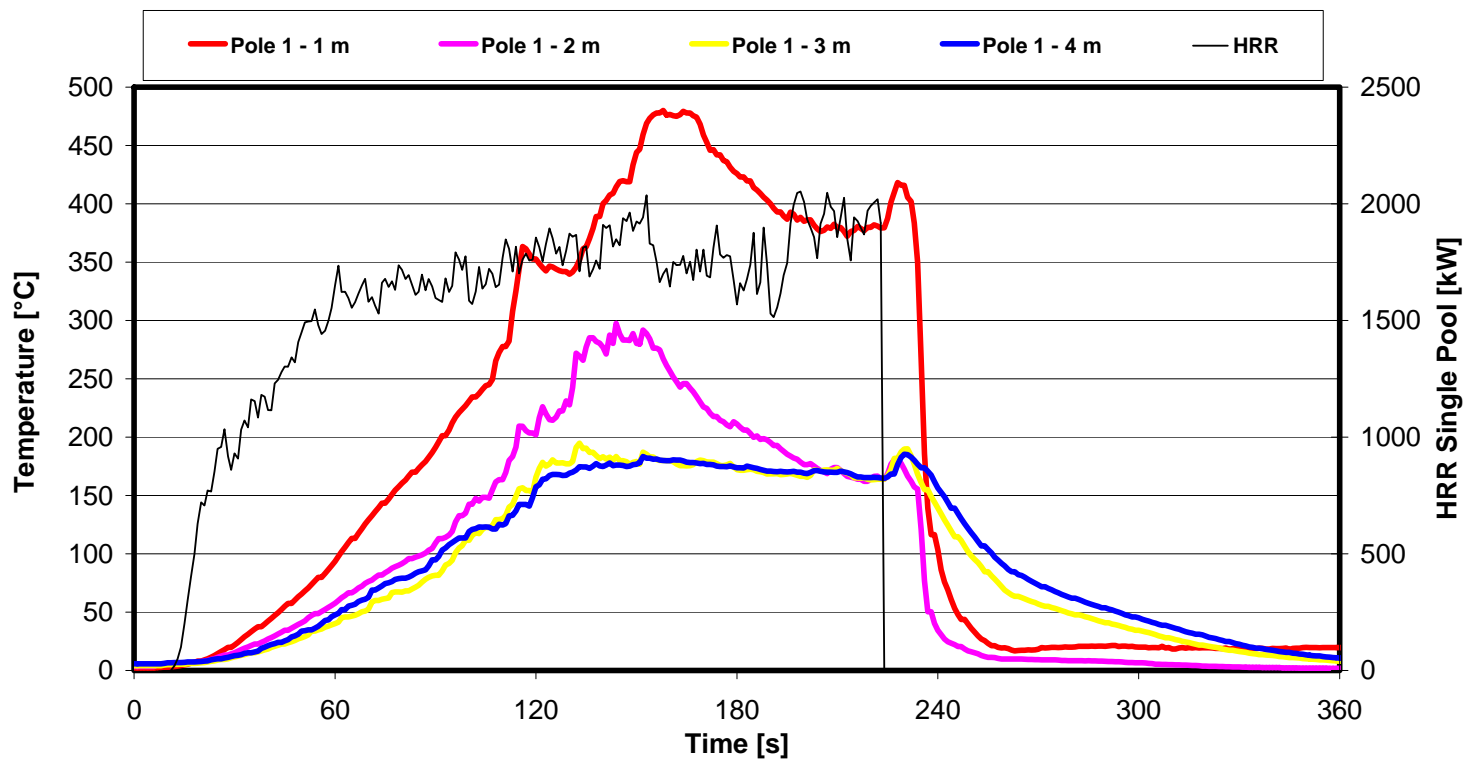

Fig. (6). Heat release rate during the pool fire test in the Rosa tunnel and temperatures measured in correspondence of the fire source at different distances from the ground. 
temperature, $\mathrm{CO}$ and $\mathrm{CO}_{2}$ concentrations, opacity and smoke velocity) before and after the mitigation system activation are shown in Fig. (7).

\subsection{Reduced Scale Experiments}

Dimensional analysis allows one to find scaling rules to extrapolate experimental conditions to similar situations with different dimensions [35-37]. When modelling buoyant smoke propagation in tunnels, the geometry of the structure is reproduced accurately and works at constant Froude number. The approach maintains the balance of inertial to buoyancy forces, but does not correctly scale many other parameters such as the fuel bed geometry, near field convection and radiative heat transfer rates, so that extrapolation of results to full scale depends is not obvious. Small scale investigations are however attractive because the experimental conditions are better controlled, and the low-cost experiments allow parametric investigations.

Fig. (9-a). shows a sketch of the small-scale tunnel built at Politecnico di Torino [13]. The scale model, reproducing a typical road tunnel with transversal ventilation system, has a modular structure and variable slope. The fire chamber module was designed according to similarity criteria derived from the local form of the entropy balance equation in dimensionless form [17]. In particular, the conservation of the entropy production number in the prototype and in the model allows one to simulate convective and radiative heat transfer rates.

To prevent low velocities in the scale model, the geometric scale factor was 1:50. The modular structure allows one to simulate tunnels of different lengths, to test longitudinal

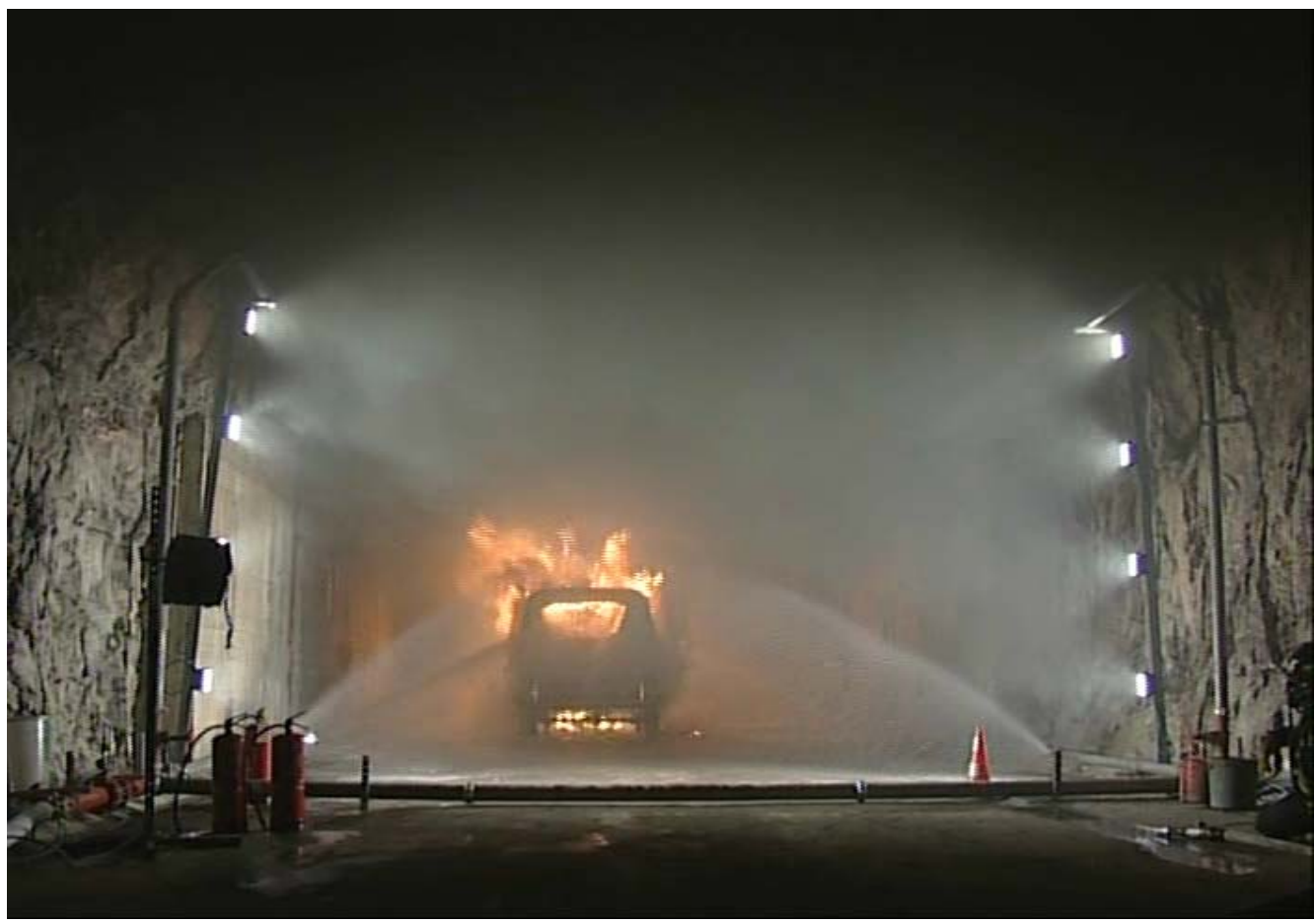

Fig. (7). Burning van and activation of the mitigation system in the Rosa tunnel.

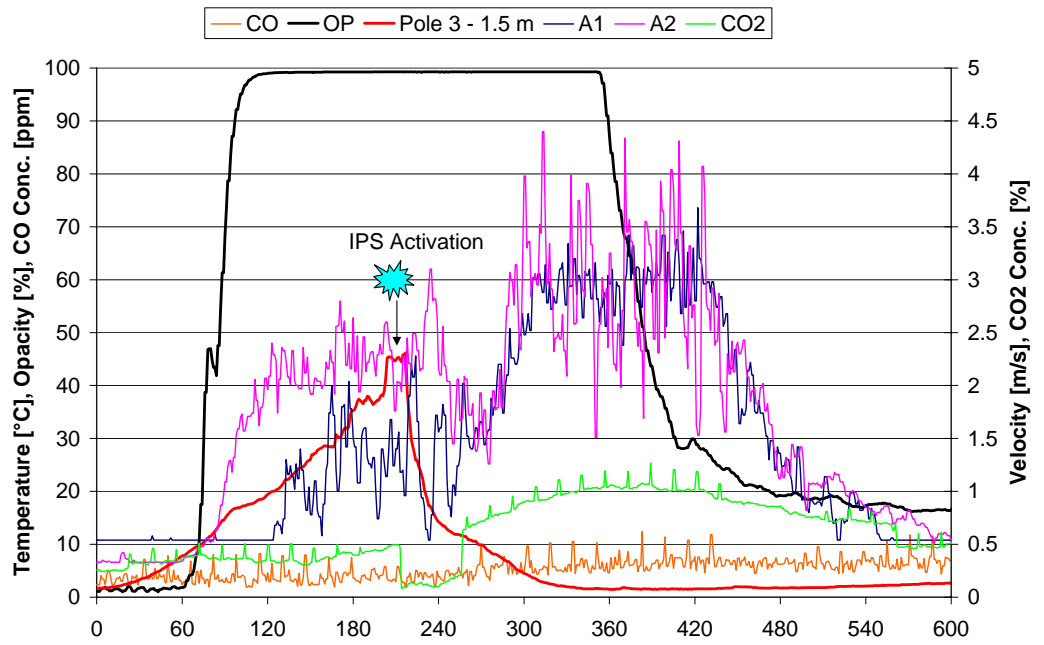

Fig. (8). Tenabilty parameters during the van test in the Rosa tunnel after activation of the mitigation system. CO: carbon monoxide concentration; $\mathrm{CO} 2$ : carbon dioxide concentration; $\mathrm{OP}$ : opacity; A1, A2: velocity measured by anemometers. 
and transverse ventilation, to evaluate the boundary conditions effects on the fire evolution.

The roadway, the back wall and the ceiling of any module are in concrete, whereas the forehead and the dome of the ventilation duct are in pyroceramic and pyrex glasses, respectively, in order to allow visual inspection and recording of the flow patterns visualized by means of light blades and seeding with titanium oxide and aluminium particles (see an example in Fig. 9-b).

Arrays of thermal resistance sensors were used to measure velocity and temperature profiles, while radiative heat transfer was measured by a pyrometer; differential pressure transducers were placed at the two ends of the module and at the extraction hood. The mass fraction of burnt fuel was measured by a digital scale. The mean value of the smoke velocity, the geometrical dimensions of the flame, and the thickness of the smoke layer were determined by digital image processing.

\section{MODELLING FIRES IN TUNNELS}

Tunnel fire models aiming at the estimation of its effect on tunnel users and on safety scenarios are sorted into thermodynamic models, or zone models, which are based on the thermodynamic analysis of open systems, and solved with spreadsheets or mathematics solvers, and field models, i.e. one-, two- or three-dimensional CFD models, solved with commercial or open source codes. The main features of these approaches are reviewed in [16].

All of the model inputs are related to a peculiar fire scenario, including the position of fire in the tunnel, the size of the fire source and the growth rate, and the ventilation conditions. Model outputs (e.g. temperature field, smoke movement and concentration) can then be used to determine the "hazard flow" along the tunnel itself. Inputs can be either deterministic (e.g., single values of the HRR, deterministic growth rates, assigned ventilation conditions) or stochastic (i.e., characterisation of the same quantities in terms of distribution functions). In both cases, models can be solved through appropriate integration methods.

\subsection{Fire Modelling}

The HRR of tunnel fire sources can be influenced by several variables: the amount, geometry, shape and type of burning material (fire load); the ventilation conditions (velocity field); the tunnel geometry, slope, cross-sectional area; the properties of the tunnel surface materials; the existence mitigation and suppression systems, or fire brigade intervention. Fig. (10) shows the relations between the standard design criteria for the longitudinal ventilation system and the heat release rate enhancement.

During the past 15 years, the Flame Research Group at Politecnico di Torino has been gathering information on HRRs in tunnel fires from both full-scale and reduced-scale experiments, as well as from the results of other research groups. On the basis of these results, models to predict the HRR were developed to be used both in the design of new tunnels and in the upgrading of existing ones. In particular, design fires can be sorted into: (i) linear curve-linear growth and decay with constant maximum HRR duration; (ii) quadratic curves-quadratic growth and exponential decay with constant maximum HRR duration; (iii) exponential curveexponential growth and decay of HRR.

The first type is recommended in the French tunnel design guidelines [9], the second type is recommended in ANAS guidelines [25], and the third is applicable to controlled fuel fires and fires with small, constant duration of the HRR [16].

The quadratic curves-quadratic growth and exponential decay model has the following structure:
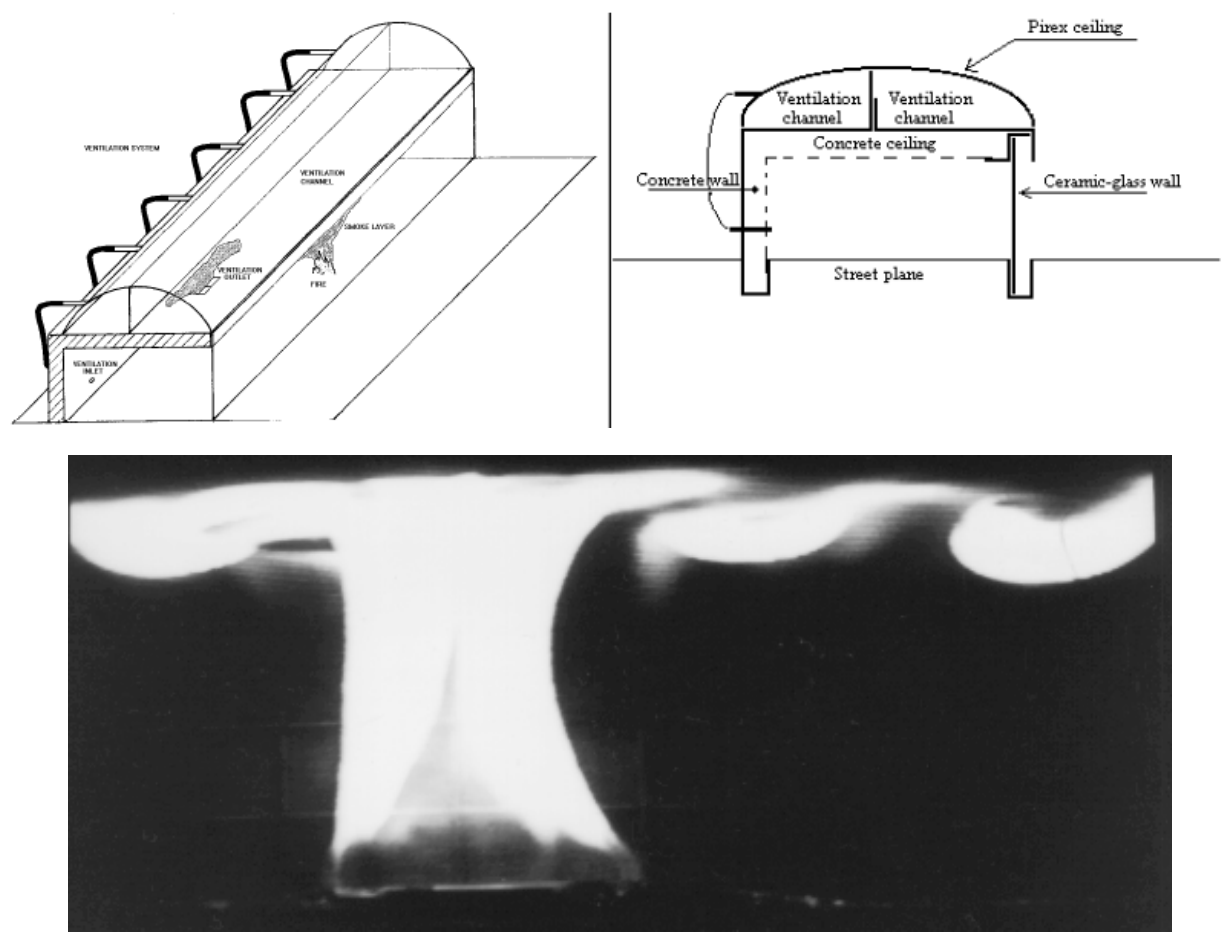

Fig. (9). Reduced scale motorway tunnel (a) and visualization of the smoke plume propagation (b). 


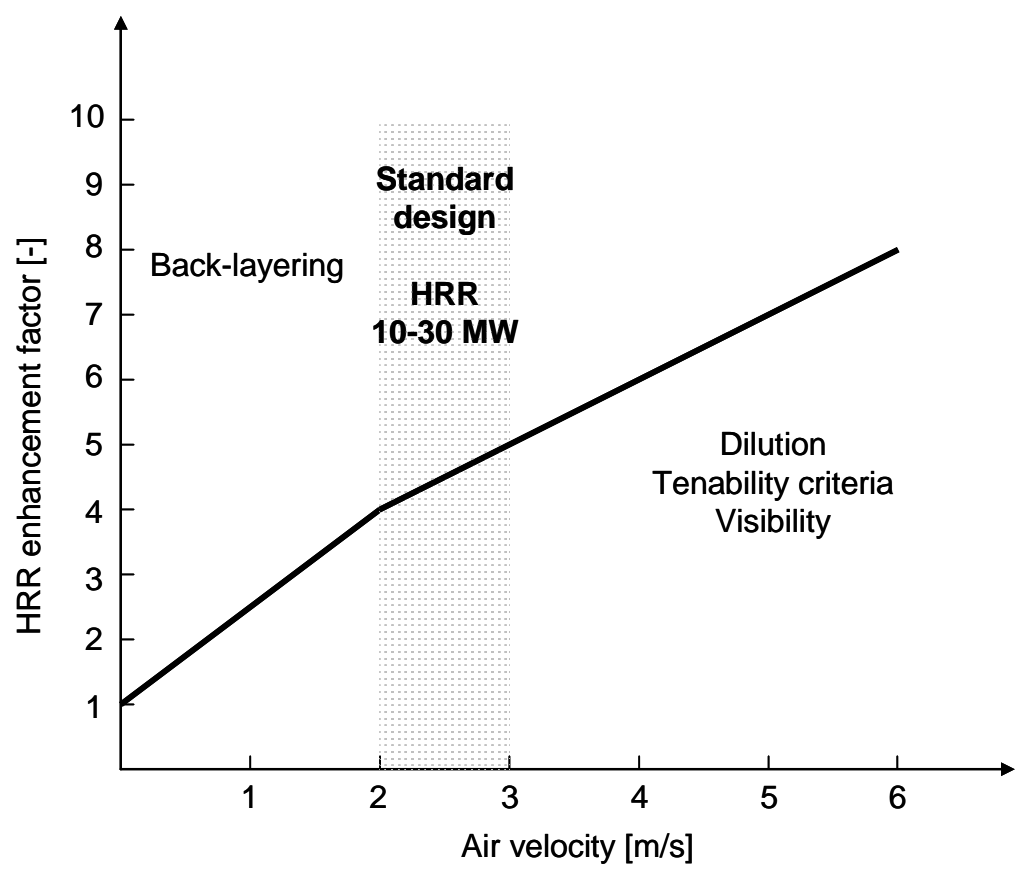

Fig. (10). HRR enhancement caused by the ventilation conditions (air velocity).

$\dot{Q}(t)=\left\{\begin{array}{lc}\alpha t^{2} & 0 \leq \mathrm{t}_{1} \\ \alpha t_{1}^{2}=\dot{\mathrm{Q}}_{\mathrm{M}} & \mathrm{t}_{1} \leq t \leq t_{2} \\ \dot{\mathrm{Q}}_{\mathrm{M}} \mathrm{e}^{-\beta\left(\mathrm{t}_{2}\right)} & \mathrm{t} \geq \mathrm{t}_{2}\end{array}\right.$

where $\dot{Q}_{M}$ is the maximum power, $\mathrm{t}_{1}$ and $\mathrm{t}_{2}$ are characteristic times, and $\alpha$ and $\beta$ growth coefficients. Some indicative parameters for different fire sources are reported in Table 3 . It is interesting to observe that since real fires can be any combination of design fires, these coefficients must be characterised in terms of distribution functions in real scenarios.

Table 3. Indicative Parameters for Different Fire Sources

\begin{tabular}{|c|c|c|c|}
\hline Source & $\dot{Q}$ & $\alpha$ & $\beta$ \\
\hline \hline & MW & $\mathrm{kW} / \mathrm{s}^{2}$ & $1 / \mathrm{s}$ \\
\hline Cars & $4-8$ & $0.01-0.012$ & 0.001 \\
\hline Bus & $15-30$ & $0.1-0.15$ & 0.0007 \\
\hline \multirow{2}{*}{ Truck } & & 0.09 (PIARC) & \\
\cline { 3 - 3 } & \multirow{2}{*}{$15-150$} & 0.5 (EUREKA) & \multirow{2}{*}{0.02} \\
\cline { 3 - 3 } & & 0.6 (Memorial) & \\
\cline { 3 - 4 } & & 1 (Runehamar) & \multirow{2}{*}{0.001} \\
\hline Train & $10-15$ & $0.01-0.015$ & 0.001 \\
\hline Subway wagon & $30-40$ & $0.3-0.4$ & \\
\hline
\end{tabular}

Most HRR predictions do not take into account the initial growth period, which however should be considered in case of flames spreading over more vehicles.
The total power of the fire includes a convective and a radiative part, which in first approximation is about $30 \%$ of the maximum power.

The smoke generation rate in case of axisymmetric smoke plume can be estimated as [16]:

$$
\dot{m}_{S}=0.71 \dot{Q}^{1 / 3} z^{5 / 3}\left(1+0.026 \dot{Q}^{2 / 3} z^{-5 / 3}\right)
$$

where $\mathrm{z}$ is the height of the smoke layer. Note that because Eq. (2) is an explicit function of the HRR, it must be considered a probabilistic variable and characterised in terms of a distribution function.

Oxygen consumption is approximately $1 \mathrm{~kg}$ per $13 \mathrm{MJ}$ of energy generated by fire, while $\mathrm{CO}_{2}$ production is about $1 \mathrm{~kg}$ per 10 MJ. Production of poisoning gas CO depends on the ventilation conditions: realistic estimates for the ratio $[\mathrm{CO}]$ : $\left[\mathrm{CO}_{2}\right]$ are 1:5 (poor ventilation) and 1:25 (good ventilation).

\subsection{Smoke Layer Modelling}

Depending on the ventilation conditions, the smoke plume can be either symmetric (natural ventilation) or asymmetric (longitudinal ventilation), with the main flow downstream of the fire source and a backlayer flow upstream. The backlayering length is defined as the distance between the fire source and the axial position where buoyancy equals inertia (stagnation point):

$\frac{\left(\rho_{S}-\rho_{A}\right) g h}{2}=\frac{\rho_{A} u^{2}}{2}$

where $\rho_{\mathrm{S}}$ and $\rho_{\mathrm{A}}$ are the smoke and the air densities, $\mathrm{h}$ is the smoke layer thickness, and $\mathrm{u}$ is the ventilation velocity. Introducing the ideal gas law into Eq. (3) yields: 


$$
\frac{\Delta T}{T_{A}}=\frac{u^{2}}{g \gamma H}
$$

where $\mathrm{H}$ is the tunnel height, and $\gamma=h / H$ has values in the range $0.2 \leq \gamma \leq 0.4$.

The maximum smoke temperature can be estimated as:

$$
\frac{\Delta T_{M A X}}{T_{A}}=A\left(\frac{\dot{Q}_{*}^{2 / 3}}{F r^{1 / 3}}\right)^{B}
$$

where $F r=u^{2} / g H$ is the Froude number, and $\dot{Q}_{*}$ is a dimensionless HRR defined as:

$\dot{Q}_{*}=\frac{\dot{Q}}{\rho c_{P} T_{A} g^{1 / 2} H^{5 / 2}}$

The empirical constants A and B are given in Table 4.

Table 4. Empirical Constants for Eq. (5)

\begin{tabular}{|c|c|c|}
\hline$\left(\frac{\dot{Q}_{*}^{2 / 3}}{F r^{1 / 3}}\right)$ & A & B \\
\hline \hline$<1.35$ & 1.77 & 1.2 \\
\hline$>1.35$ & 2.54 & 0 \\
\hline
\end{tabular}

The backlayering length can be calculated only if the temperature distribution along the tunnel is known. This can be obtained from the energy conservation equation as:

$$
\frac{\Delta T(x)}{\Delta T_{M A X}}=\exp \left(-\frac{x}{\Lambda}\right)
$$

where $\Lambda=\dot{m} / \lambda P$, temperature differences are taken with respect to the ambient air temperature, $\dot{m}$ is the mass flux of smoke per unit cross-sectional area, $\lambda$ is the heat transfer coefficient, and $\mathrm{P}$ the perimeter of the tunnel. To calculate the smoke mass flux, one must estimate the entrainment velocity, defined as:

$$
w_{E}=\delta\left(u-u_{S}\right)
$$

where $\delta=0.00015, \mathrm{u}_{\mathrm{S}}$ is the smoke velocity, and u the ventilation velocity. Because the entrainment mass flux is much smaller than the initial smoke mass flux, this quantity can be considered constant.

However, calculating the coefficient $\Lambda$ using the procedure described above is not easy, in particular because the heat transfer coefficient $\lambda$ cannot be estimated with standard heat transfer correlations. Comparing a large set of values obtained from small- and full-scale experiments, as well as several numerical simulations using field models, it was possible to conclude that $45 \leq \Lambda \leq 60$.

Another straightforward way to obtain the smoke layer temperature distribution descends from the analogy between the tunnel and a heat exchanger:

$$
T_{S}(x, t)=T_{A}+\left[T_{S}(0, t+x / u)-T_{A}\right] \exp \left(-\frac{\lambda P}{\dot{m} c_{P}} x\right)
$$

Because the thermal power transferred by convection is about $70 \%$ of the total, at the fire location $(x=0)$ the smoke layer temperature is given by:

$T_{S}(0, t)=T_{A}+\frac{0.7 \dot{Q}(t)}{\dot{m} c_{P}}$

Because the smoke layer temperature is explicitly dependent on the heat release rate, which is a stochastic variable, it should be considered as a probabilistic quantity, and characterised in terms of a distribution function.

Figs. (11 and 12). compare the results of calculations carried out using in one case deterministic values for the parameters defining the design fires (Table 3 ), and in the other case a log-normal distribution function having the same mean value. The difference between the two approaches is significant, and proves that risk analysis in tunnels should be based on probabilistic methods in order to take into account of the stochastic nature of fire phenomena.

\section{CONCLUSIONS}

The knowledge built-up through years of research (and through disasters occurred in the past) has taught us some lessons, which are summarised below.

First of all, risk analysis methods to design and operate road and railway tunnels should incorporate the principles and the methods of the classical deterministic fire safety engineering (scenario analysis) into a probabilistic framework. Whilst these concepts have been fully incorporated into the Italian standards $[25,38]$, their practical application is still ambiguous so far.

The use of prescriptive guidelines derived from common practice and from professional or corporate experience in tunnels design may appear advantageous if one assumes that all tunnels are similar. However, this is not necessarily the case, and non-typical tunnels should be considered individually. Moreover, the ultimate effects of regulations and emergency procedures are highly scenario-dependent.

For the same reason, the use of CFD simulations made by practitioners with limited knowledge of tunnel systems should be discouraged.

Ventilation systems have been installed in road tunnels for more than one century, so that it is not surprising that the earliest fire safety procedures attempted at controlling and directing the smoke flow using ventilation. Unfortunately, this is not always the best thing to do in emergencies: in fact, it has been shown that the high air flow rates needed to drive the smoke away would create more severe conditions by feeding oxygen to the fire. In addition, the incorrect use of ventilation would determine even more casualties.

According to another common belief, the use of sprinkler systems would hamper people evacuation and might even decrease the tunnel tenability by generating steam and destroying the smoke stratification. However, a number of recent studies to assess the effectiveness of water-based suppression and mitigation systems (both rainfall systems and water mist) have established that while it is true that these systems destroy the smoke stratification, they also reduce the fire size and stop flames spreading, which eventually induces a smaller heat release rate and a smaller smoke generation. 

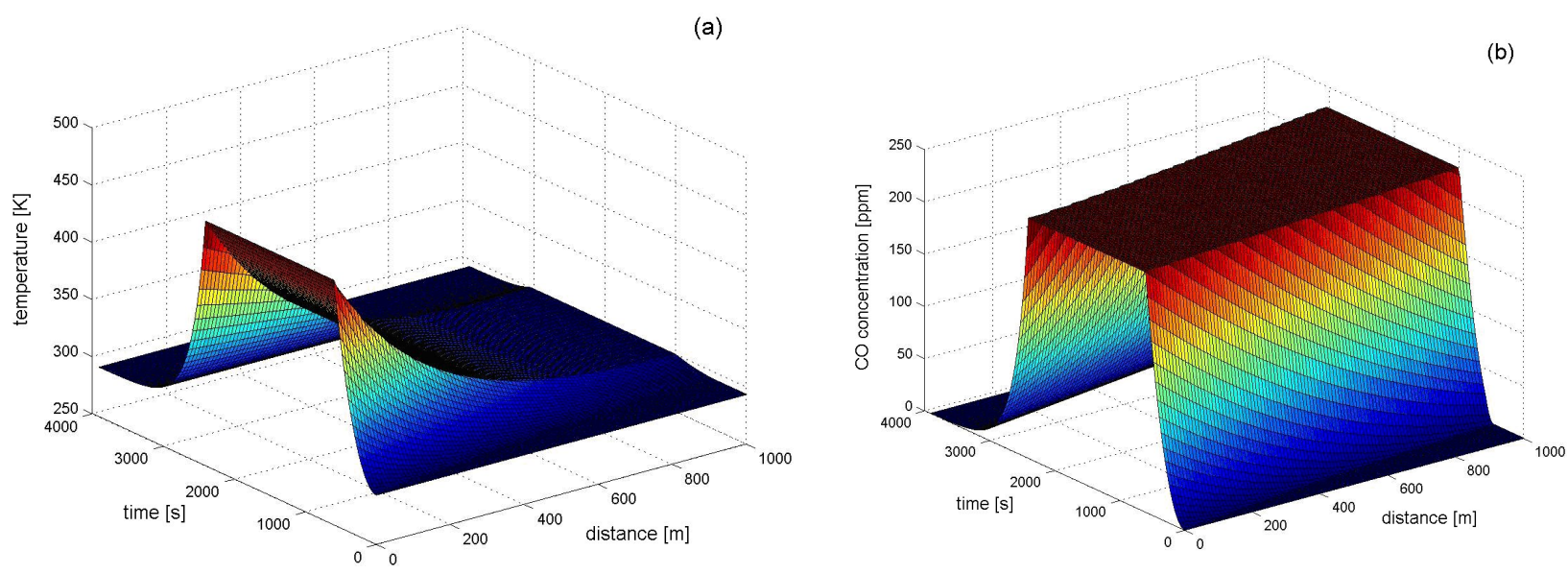

Fig. (11). Temperature (a) and CO concentration (b) distributions along the tunnel for a $30 \mathrm{MW}$ fire, calculated using deterministic values for the model parameters.
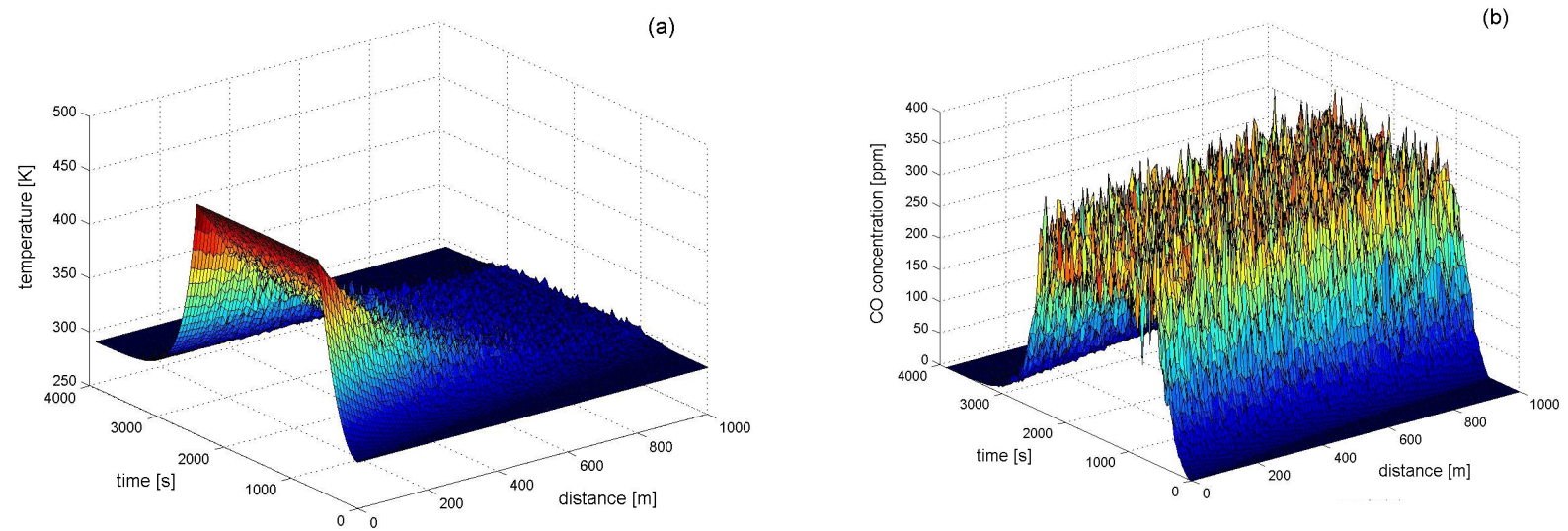

Fig. (12). Temperature (a) and CO concentration (b) distributions along the tunnel for a $30 \mathrm{MW}$ fire, calculated using a distribution function for the model parameters.

\section{REFERENCES}

[1] UN Economical Council Recommendations of the Group of Experts on Safety in Road Tunnels, Trans. AC, 7/9, 2001.

[2] Directive 2004/54/EC of the EU Parliament/EU Council, On minimum requirements for tunnels in the Trans-European Road Network, $29^{\text {th }}$ April 2004

[3] G. A. Colombo, Lesson learnt from tunnel accidents, Report EUR $19815 \mathrm{EN}, 2001$.

[4] P. Duffé, M. Marec, Task force for technical investigation of the 24 March 1999 fire in the Mont Blanc vehicular tunnel, Minister for Internal Affairs, Ministry for Equipment, Transportation and Housing, General Inspector of the Administration, Board of Bridges and Highways, Report 30 $0^{\text {th }}$ June 1999.

[5] E. Cafaro, Dossier ANAS sull'Incidente del Traforo del Monte Bianco (Commissione Basile) - Allegato Tecnico, Agosto 1999.

[6] A. Leitner, The fire catastrophe in the Tauern tunnel: experience and conclusions for the Austrian guidelines, Tunnelling Underground Space Technology, vol. 16, p. 217, 2001.

[7] A. Voeltzel, A. Dix, Comparative analysis of the Mont Blanc, Tauern and Gotthard tunnel fires, Routes Roads no. 324, 2004.

[8] D. Lacroix (ed), Fire and Smoke Control in Road Tunnels. PIARC, 1999.

[9] D. Lacroix, New French Recommendations for fire ventilation in road tunnels, $9^{\text {th }}$ Int. Conf. on Aerodynamics and Ventilaion of Road Tunnels, Aosta, Italy, 6-8 October 1997.

[10] Norwegian Road Authorities, Building road tunnels, Handbook 021, Pb 8142 Dep., 0033 Oslo, 2002.
[11] Australasian Fire Authorities Council, Fire safety guidelines for road tunnels, ARAC Limited, Boxhill Victoria 3128 Australia 2001.

[12] H. Ingason, A. Lönnermark, "Heat Release Rates from Heavy Goods Vehicle Trailers in Tunnels", Fire Saf. J., vol. 40, pp. 646$668,2005$.

[13] E. Cafaro, V. Bennardo, V. Ferro, A. Saluzzi, "Physical modelling and numerical simulation of fire events in road tunnels", Proc. $9^{\text {th }}$ Int. Conf. on Aerodynamic and Ventilation of Vehicle Tunnels, pp. 649-668, Aosta, 1997.

[14] E. Cafaro, Prova a fuoco in galleria stradale, Ministero dell'Interno - Servizio documentazione e relazioni pubbliche, Roma, 2001.

[15] E. Cafaro, Physical and mathematical modelling of fires in enclosures, Politeko, Turin, 2002.

[16] E. Cafaro, Progettazione termo-fluido-dinamica del sistema galleria, Politeko, Turin, 2003.

[17] E. Cafaro, L. Stantero, "Fire smoke movements in tunnel scale models: theory and experimental observations", Int. J. Heat Technol., vol. 21, pp. 159-164, 2003.

[18] E. Cafaro, M. Masiero, "Testing tunnel fire mitigation systems", T\&T Int, vol. 36, pp. 39-42, 2004.

[19] E. Cafaro, C. Cima, L. Stantero, Rosa tunnel full scale fire tests. Indoor Protection System IPS, Kidde Italia S.p.A. Report 125 Dip. Energetica, Politecnico di Torino, 2005.

[20] E. Cafaro, C. Cima, L. Stantero, A. Arelli, "An Innovative Tunnel Fire Protection System", Tunnel Manag Int, vol. 8, no. 3, pp. 3544, 2005.

[21] E. Cafaro; C. Cima L. Stantero; A, Arelli, Tunnel fire mitigation system: Full scale tests, Int. Conference on Tunnel Protection and 
Security against Fire and other Hazards, Torino 15-17 Maggio 2006.

[22] E. Cafaro, A. Focaracci, M. Guarascio, L. Stantero, Quantitative risk analysis for tunnel safety, Tunnel Manage Int., vol. 9, no. 3-4, pp. 32-40, 2006.

[23] E. Cafaro, L. Stantero, A. Focaracci, M. Guarascio, Progetto della sicurezza per le gallerie stradali e decreto di recepimento della direttiva europea, Le Strade, n. 11, 2006.

[24] E. Cafaro, C. Cima, L. Stantero, T. Taurino, Progetto della sicurezza antincendio nelle gallerie stradali: sistemi di sicurezza ed analisi di rischio, Gallerie e Grandi Opere Sotterranee, vol. 29, pp. 43-52, 2007.

[25] ANAS S.p.A., Linee guida per la progettazione della sicurezza nelle gallerie stradali, Suppl. Strade \& Autostrade No. 61, EdiCem, Milan, 2007.

[26] E. Cafaro, A. Focaracci, Analisi di rischio o analisi delle conseguenze, Le Strade, n. 10, pp 106-121, 2008.

[27] V. Bertola, E. Cafaro, Deterministic-stochastic approach to compartment fire modelling, Proc. Royal Soc. A., vol. 465, pp. 1029$1041,2009$.

[28] A. Beard, R. Carvel (eds.), The Handbook of Tunnel Fire Safety, Thomas Telford, London. 2005.
[29] C. Les, J. Bettis, R. Jagger, A review of available data and models for tunnel fires, Health and Safety Executive Project Report IR/L/FR/94/12, Health Safety Laboratory, Buxton, 1995.

[30] A. Haertz, Fire tests in the Ofeneg tunnel in 1965, Proc. Int. Conf on Fires in Tunnels, Boras, Sweden, 10/11 October 1994.

[31] Fires in transport tunnels: report on full-scale tests, EUREKA Project EU495 (FIRETUN), Dusseldorf, 1995

[32] Fire Ventilation Test Programme - Comprehensive Test programme, Pearson Brinckerhoff, 1996.

[33] Federal Ministry of Construction and Technology, Fire tests in a tunnel (Zwenberg tunnel), Road Research, vol. 50, 1976.

[34] Vibe, Brennverlauf und Kreisprozess von Verbrennungsmotoren, VEB-Verlag Technik, Berlin, 1970.

[35] D.B. Spalding, The art of partial modeling, Proc. $9^{\text {th }}$ Symp. on Combustion, pp. 883-843, N.Y. Academic, 1963.

[36] F. Williams, Scaling mass fires, Fire Res. Abstr. Rev., vol. 11, pp. $1-22,1969$

[37] J. G. Quintiere, "Scaling applications in fires reaction", Fire Saf. J., vol. 15, pp. 3-29, 1989.

[38] Decreto Legislativo 5 ottobre 2006, n. 264 Attuazione della direttiva $2004 / 54 / \mathrm{CE}$ in materia di sicurezza per le gallerie della rete stradale transeuropea, Gazzetta Ufficiale n. 235, S.O. n. 195, 9th October 2006.

(c) Cafaro and Bertola; Licensee Bentham Open.

This is an open access article licensed under the terms of the Creative Commons Attribution Non-Commercial License (http://creativecommons.org/licenses/ by-nc/3.0/) which permits unrestricted, non-commercial use, distribution and reproduction in any medium, provided the work is properly cited. 